\title{
Paucisymptomatic gastric anisakiasis: endoscopical removal of Anisakis sp. larva
}

\author{
Rossella Palma1, Simonetta Mattiucci ${ }^{2}$, Cristina Panetta ${ }^{1}$, Marilena Raniolo', Fabio Massimo \\ Magliocca $^{3}$, Stefano Pontone ${ }^{1}$ \\ 1Department of Surgical Sciences, Sapienza University of Rome, Rome 00161, Italy. \\ 2Department of Public Health and Infectious Diseases, Section of Parasitology, Sapienza University of Rome, Rome 00161, Italy. \\ ${ }^{3}$ Experimental Medicine and Pathology, Sapienza University of Rome, Rome 00161, Italy.
}

Correspondence to: Dr. Stefano Pontone, Department of Surgical Sciences, Sapienza University of Rome, V.le Regina Elena n. 324, Rome 00161, Italy. E-mail: stefano.pontone@uniroma1.it

How to cite this article: Palma R, Mattiucci S, Panetta C, Raniolo M, Magliocca FM, Pontone S. Paucisymptomatic gastric anisakiasis: endoscopical removal of Anisakis sp. larva. Mini-invasive Surg 2018;2:1. http://dx.doi.org/10.20517/2574-1225.2017.40

Received: 28 Aug 2017 First Decision: 9 Oct 2017 Revised: 14 Dec 2017 Accepted: 19 Dec 2017 Published: 16 Jan 2018

Science Editor: Charles F. Bellows Copy Editor: Jun-Yao Li Production Editor: Huan-Liang Wu

\begin{abstract}
Anisakiasis is increasing worldwide, even in Europe and in the Mediterranean region due to the increased practice of raw fish consumption. Usually, a detailed food history is the key to the diagnosis. A 52-year-old woman affected by pathological obesity underwent esophagogastroduodenoscopy (EGD) for a 1-year history of epigastric pain. In the gastric fundus, an Anisakis sp. larva, was casually detected. The nematode was successfully removed with a biopsy forceps. In this case, the finding of the parasite was casual, being detected during an accurate EGD performed for a 1-year history of epigastric pain in the patient.
\end{abstract}

Keywords: Endoscopy, epigastric pain, zoonotic parasite, Anisakis

\section{INTRODUCTION}

Anisakiasis is a fish-borne parasitic zoonosis associated with the consumption of raw or insufficiently cooked infected fish. The human disease is the result of the accidental ingestion of the third stage larva of the parasite that is infective to fish and squids. Most of the cases of Anisakiasis have been reported in Japan where there is a great consumption of raw fish, but the number of cases is increasing worldwide, even in Europe and in the Mediterranean region due to the increased practice of raw fish consumption. The anisakiasis is considered a rare disease even if the incidence is probably underestimated in many countries. As is reported in literature, the nematode is often hidden among gastric folds, and can be

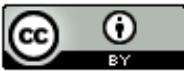

(C) The Author(s) 2018. Open Access This article is licensed under a Creative Commons Attribution 4.0 International License (https://creativecommons.org/licenses/by/4.0/), which permits unrestricted use, sharing, adaptation, distribution and reproduction in any medium or format, for any purpose, even commercially, as long as you give appropriate credit to the original author(s) and the source, provide a link to the Creative Commons license, and indicate if changes were made. 


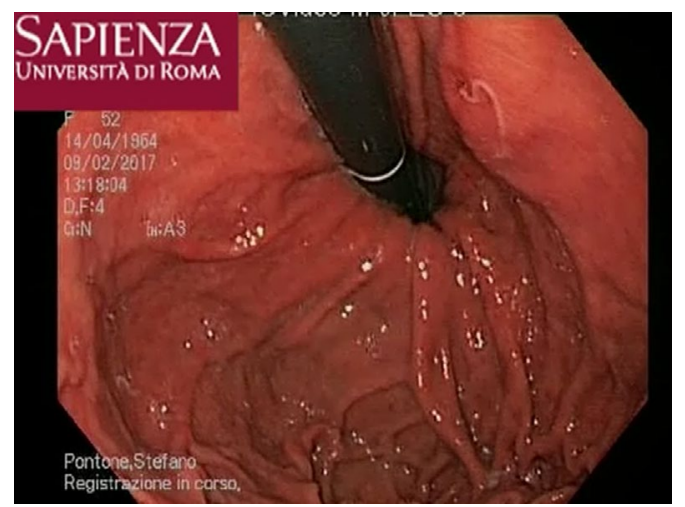

Figure 1. The Anisakis larva visualization in the gastric fundus during retrovision maneuver close to the mucosal erosion

confused with gastric mucus and the gastric detection could be difficult using white light endoscopy ${ }^{[1]}$. For this reason, narrow band imaging is proposed in order to increase the nematode detection during esophagogastroduodenoscopy (EGD $)^{[2]}$. In gastric anisakiasis, which is more frequent, symptoms occur just a few hours after raw fish consumption ${ }^{[3,4]}$. The typical clinical presentation is acute epigastric pain within $12 \mathrm{~h}$ after the ingestion of infected fish, occasionally accompanied by nausea, vomiting and fever ${ }^{[5]}$. Diagnosis is currently performed by the molecular identification of the parasite removed by gastric endoscopy associated to a seroimmunological assay. Also, a delayed allergic manifestation, named gastroallergic anisakiasis $(\mathrm{GAA})^{[6,7]}$, may occur in association with rash, urticaria, isolated angioedema and anaphylaxis ${ }^{[8]}$. In this respect, Daschner et al. ${ }^{[6]}$ described the GAA as an acute allergic reaction with symptoms of hypersensitivity appearing several hours after the ingestion associated with penetration of larvae into the gastric mucosa ${ }^{[9]}$. In addition, the presence of an IgE antibody response in individuals with no apparent symptoms has been also detected 1 month after the acute GAA episode ${ }^{[10]}$. It has been suggested that a variety of effector molecules form the allergic host defence response. One important step in the activation of this defence mechanism against Anisakis spp. and its antigens are the activation of Th2, leading to the secretion of cytokines, including interleukin (IL)-4, IL-5, IL-9 and IL-13 cells, which promote mast cell hyperplasia and eosinophilia. A recent study of Mattiucci et al ${ }^{[11]}$ has shown that Ani s 7-like and Ani s 13-like, detected in the sera samples, could be considered as major antigens in the diagnosis of allergic anisakiasis caused by $A$. pegreffii.

This report emphasizes the importance of investigating into raw fish ingestion in patients with signs and symptoms compatible with Anisakis sp. infection.

\section{CASE REPORT}

A 52-year-old Italian woman underwent upper elective endoscopy before having a sleeve gastrectomy. She was affected by pathological obesity and underwent EGD after 12 months history of epigastric pain and gastroesophageal reflux disease. She didn't have other symptoms such as nausea, vomiting, diarrhea or fever. Upper endoscopy showed gastric mucosa hyperemia with some micro-erosions in the context of antrum, middle body and fundus. In the gastric fundus, during retrovision maneuver, a mobile white threadlike worm, Anisakis sp. larva, was casually detected close to a mucosal erosion [Figure 1]. It was strongly adherent to the gastric mucosa and it could be confused with gastric mucus. The nematode was successfully removed by a biopsy forceps [Figure 2]. A bioptic fragment of the gastric tissue mucosa, including the nematode, was included in paraffin and histological sections were stained with haematoxylin-eosin revealing close to the gastric mucosa a nematode, at its larval stage. The diameter of the body, in a transerve section [Figure 3], was around $0.30 \mathrm{~mm} \times 0.20 \mathrm{~mm}$, with a thin cuticle, lacking lateral alae. Polymiarian muscle cells at both transverse and sagittal sections were visible; lateral chords were still visible despite the fact that the worm in the histological section appeared spoiled, and the intestine was circular with a triangular lumen. In 


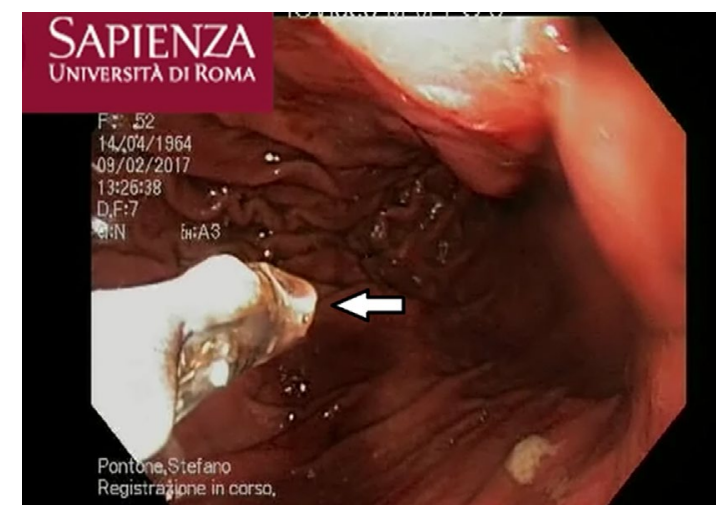

Figure 2. The nematode removal by biopsy forceps

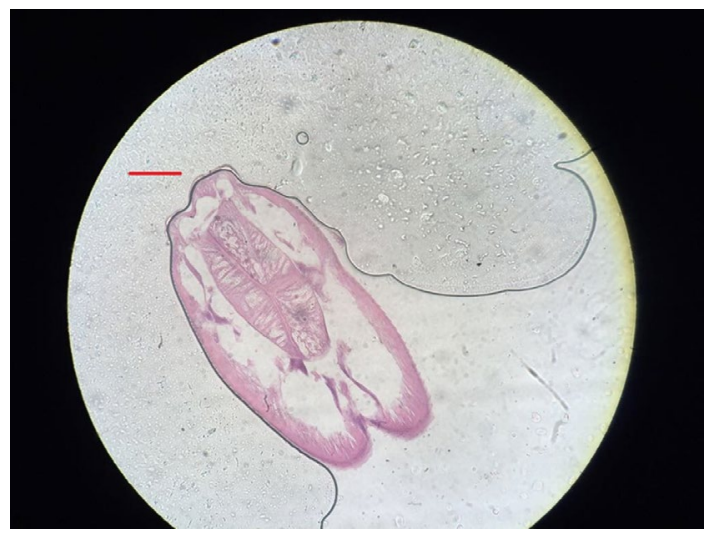

Figure 3. Transverse section of Anisakis type I larva in the gastric mucosa. Scale bar $100 \mu \mathrm{m}$

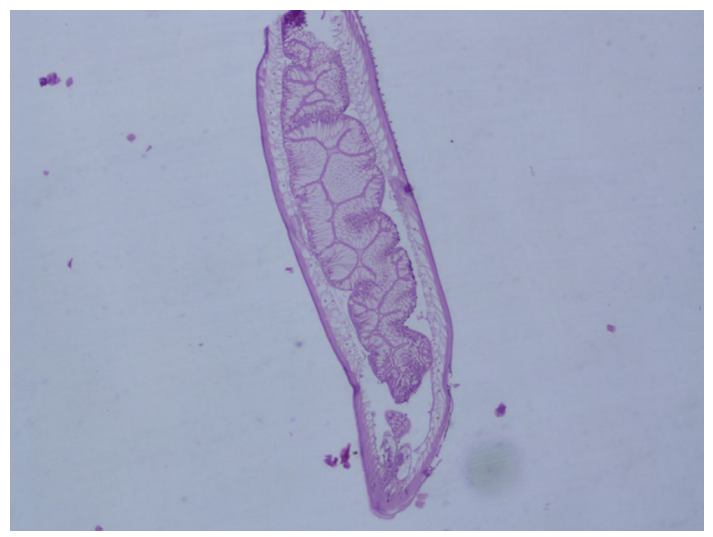

Figure 4. Sagittal section of Anisakis type I larva in the gastric mucosa. Magnification 40x

the sagittal section [Figure 4] two glandular cells found in the caudal end of the nematode were also visible. No ventricular appendix and/or intestinal caecum were found. According to those morphological features it was possible to refer the worm to a larval stage of a nematode belonging to the genus Anisakis [Video 1].

The patient reported she had eaten marinated raw anchovies at a sushi restaurant five days before the procedure and she described an intensification of gastric pain, in absence of other symptoms, after the ingestion of raw fish. 


\section{DISCUSSION}

The gastric anisakiasis affects humans following consumption of raw or undercooked seafood. A detailed food history is the key to the diagnosis because the patients develop the typical symptoms shortly after ingestion of contaminated food. The clinical history can guide the diagnosis alerting the endoscopists to look for a nematode during an upper endoscopy. In absence of a detailed anamnesis, the correlation between the occurrence of gastrointestinal symptoms and raw fish ingestion could be very difficult. Gastric anisakiasis can be suspected based on the typical presentation, which is an acute severe epigastric pain few hours after the ingestion of infected fish. The symptoms usually develop within $12 \mathrm{~h}^{[5]}$. Other clinical manifestations include nausea, vomiting, and low grade fever. There are cases in which the patients present with hematemesis from gastric ulceration ${ }^{[12-14]}$. In addition to these impressive clinical presentations, there are some asymptomatic cases identified accidentally. The diagnosis could represent a challenging problem if a correct sampling and conservation strategy were not adopted. Furthermore, as previously mentioned, the gastric detection of nematode is not easily made because it could be confused with gastric mucus. Due to the rare occurrence of this disease, inexperienced endoscopists may easily overlook larvae, because they are usually hidden between the edematous gastric folds or blend in with the gastric mucosa ${ }^{[15]}$. Thus, the true incidence of the disease could be potentially higher than what is reported in the literature as cases can go undiagnosed.

When the clinical presentation doesn't suggest the Anisakis infection or lacks of a detailed food anamnesis only an experienced endoscopist performing an accurate EGD can detect the nematode.

In the case we have reported, the diagnosis was casual and the parasite was detected during an accurate EGD performed for a one-year history of epigastralgia in an obese patient, during a routine endoscopy before surgery, in absence of gastrointestinal acute suggestive symptoms and detailed food history. This report emphasizes the importance of investigating into raw fish ingestion before diagnostic upper endoscopy, especially in patients with signs and symptoms compatible with Anisakis sp. infection. However, the accurate and specific diagnosis of the etiological agents in human anisakiasis, should be performed by molecular methodologies, which was impossible to carry out in the present study. Indeed, currently, specific and rapid DNA assay tests such as the reverse transcription-polymerase chain reaction primers-probe systems are available to be performed on fragments of larval nematodes and bioptic tissues removed by endoscopy, but also on paraffine embedded parasites. Further, the immunoblotting assay of the patient serum, joined with anamnestic investigation of the patient and use of the molecular methodologies, has been recommended in the diagnosis of human anisakiasis.

\section{DECLARATIONS}

\section{Authors' contributions}

Manuscript preparation and data acquisition: Palma R

Data analysis and parasitological classification: Mattiucci S

Literature search: Panetta C

Data acquisition: Raniolo $\mathrm{M}$

Anatomopathological classification: Magliocca FM

Study design and definition of intellectual content: Pontone S

\section{Financial support and sponsorship}

None.

\section{Conflicts of interest}

There are no conflicts of interest. 


\section{Patient consent}

The authors have obtained a written informed consent to publication, and a copy of the consent will be available if requested.

\section{Ethics approval}

The type of study does not require the consent of the ethics committee. The procedures followed were in accordance with the ethical standards of the responsible committee on human experimentation and with the Helsinki Declaration when reporting studies on human beings.

\section{Copyright}

(C) The Author(s) 2018.

\section{REFERENCES}

1. Zullo A, Hassan C, Scaccianoce G, Lorenzetti R, Campo SM, Morini S. Gastric anisakiasis: do not forget the clinical history! $J$ Gastrointestin Liver Dis 2010;19:359.

2. Taranto D, Sessa G, Tortora R, Tremolaterra F. Narrow band imaging enhancement could improve gastric anisakis detection. Dig Liver Dis 2011;43:e5.

3. Daschner A, Pascual CY. Anisakis simplex: sensitization and clinical allergy. Curr Opin Allergy Clin Immunol 2005;5:281-5.

4. Ugenti I, Lattarulo S, Ferrarese F, De Ceglie A, Manta R, Brandonisio O. Acute gastric anisakiasis: an Italian experience. Minerva Chir 2007;62:51-60.

5. Takabayashi T, Mochizuki T, Otani N, Nishiyama K, Ishimatsu S. Anisakiasis presenting to the ED: clinical manifestations, time course, hematologic tests, computed tomographic findings, and treatment. Am J Emerg Med 2014;32:1485-9.

6. Daschner A, Cuéllar C, Rodero M. The Anisakis allergy debate: does an evolutionary approach help? Trends Parasitol 2012;28:9-15.

7. Mattiucci S, Fazii P, De Rosa A, Paoletti M, Megna AS, Glielmo A, De Angelis M, Costa A, Meucci C, Calvaruso V, Sorrentini I, Palma G, Bruschi F, Nascetti G. Anisakiasis and gastroallergic reactions associated with Anisakis pegreffii infection, Italy. Emerg Infect Dis 2013;19:496-9.

8. Pontone S, Leonetti G, Guaitoli E, Mocini R, Manfredelli S, Catania A, Pontone P, Sorrenti S. Should the host reaction to anisakiasis influence the treatment? Different clinical presentations in two cases. Rev Esp Enferm Dig 2012;104:607-10.

9. Daschner A, Alonso-Gómez A, Cabañas R, Suarez-de-Parga JM, López-Serrano MC. Gastroallergic anisakiasis: borderline between food allergy and parasitic disease-clinical and allergologic evaluation of 20 patients with confirmed acute parasitism by Anisakis simplex. $J$ All Clin Immunol 2000;105:176-81.

10. Daschner A, Alonso-Gómez A, Caballero T, Suarez-De-Parga JM, López-Serrano MC. Usefulness of early serial measurement of specific and total immunoglobulin E in the diagnosis of gastro-allergic anisakiasis. Clin Exp Allergy 1999;29:1260-4.

11. Mattiucci S, Colantoni A, Crisafi B, Mori-Ubaldini F, Caponi L, Fazii P, Nascetti G, Bruschi F. IgE sensitization to Anisakis pegreffii in Italy: comparison of two methods for the diagnosis of allergic anisakiasis. Parasite Immunol 2017;39:12440.

12. Lee EJ, Kim YC, Jeong HG, Lee OJ. The mucosal changes and influencing factors in upper gastrointestinal anisakiasis: analysis of 141 cases. Korean J Gastroenterol 2009;53:90-7. (in Korean)

13. Kang DB, Park WC, Lee JK. Chronic gastric anisakiasis provoking a bleeding gastric ulcer. Ann Surg Treat Res 2014;86:270-3.

14. Goto Y, Takahashi N, Yoshimitsu M, Matano Y. Acase of gastric anisakiasis with hemorrhagic gastric ulcer and ulcerative scarring. Nihon Shokakibyo Gakkai Zasshi 2014;111:2021-4. (in Japanese)

15. Shimamura Y, Muwanwella N, Chandran S, Kandel G, Marcon N. Common symptoms from an uncommon infection: gastrointestinal anisakiasis. Can J Gastroenterol Hepatol 2016;2016:5176502. 